\title{
GCU
}

Glasgow Caledonian

University

University for the Common Good

\section{Developing high performance working through case study evidence}

Grant, Kirsteen; Maxwell, Gillian

Published in:

Development and Learning in Organisations

DOI:

10.1108/DLO-03-2017-0028

Publication date:

2018

Document Version

Author accepted manuscript

Link to publication in ResearchOnline

Citation for published version (Harvard):

Grant, K \& Maxwell, G 2018, 'Developing high performance working through case study evidence', Development and Learning in Organisations, vol. 32, no. 2, pp. 5-8. https://doi.org/10.1108/DLO-03-2017-0028

\section{General rights}

Copyright and moral rights for the publications made accessible in the public portal are retained by the authors and/or other copyright owners and it is a condition of accessing publications that users recognise and abide by the legal requirements associated with these rights.

Take down policy

If you believe that this document breaches copyright please view our takedown policy at https://edshare.gcu.ac.uk/id/eprint/5179 for details of how to contact us. 


\section{Devélopment and Learning \\ Emerald in Organizations: \\ An International Journal}

\section{Developing high performance working through case study evidence}

\begin{tabular}{|r|l|}
\hline Journal: & Development and Learning in Organizations \\
\hline Manuscript ID & DLO-03-2017-0028.R4 \\
\hline Manuscript Type: & Authored Paper \\
\hline Keywords: & $\begin{array}{l}\text { High performance working, High performance work practices, High } \\
\text { performance }\end{array}$ \\
\hline \multicolumn{2}{|l}{} \\
\hline
\end{tabular}

SCHOLARONE ${ }^{\text {I" }}$

Manuscripts 


\title{
Developing high performance working through case study evidence
}

\author{
Abstract \\ Purpose \\ The article theoretically proffers and empirically evidences five inter-related high \\ performance working (HPW) groupings of value to practitioners interested in developing \\ HPW in their organizations. \\ Design/methodology/approach \\ The empirical research is based on three UK-based qualitative case studies. Data are drawn \\ from nine in-depth interviews with managers (three from each case) and three subsequent \\ focus groups (one in each case). Focus groups comprised six, eight and four employee (non- \\ manager) interviewees respectively.

\section{Findings} \\ The empirical findings validate the theoretical importance of the five identified HPW \\ groupings. More, they imply a number of relationships within and between the five \\ groupings, confirming the need to view the groupings collectively and dynamically.

\section{Originality/value} \\ The five HPW groupings provide a foundation for further research to closely evaluate the \\ dynamism within and across the groupings. They also offer practical types of HR \\ interventions and actions for practitioners to evaluate the strengths and weaknesses of HPW \\ in their organizations.
}

Keywords: High performance; high performance working; high performance work practices Article Classification: Research Paper 


\section{Developing high performance working through case study evidence}

\section{Introduction}

This article proposes and discusses five inter-related high performance working (HPW) groupings of value to practitioners interested in developing HPW in their organizations.

\section{High Performance Working}

HPW is a sometimes contentious notion that dominates human resource management literature (Boxall, 2012). Belt and Giles (2009: 3) define HPW as 'a general approach to managing organizations that aims to stimulate more effective employee involvement and commitment in order to achieve high levels of performance'. HPW requires a contingent bundle(s) of HPW practices, collectively referred to as a HPW system. HPW practices that comprise these systems can be classified as human resource (HR) interventions and actions that contribute, at an operational level, to the totality of high performance working at an organizational level (Grant and Maxwell, 2015). Achievement of HPW therefore calls for a deliberate focus on ensuring effectiveness in not only how people are led and managed strategically in their organization, but also in how work and jobs are designed operationally to enable higher levels of employee participation and skills utilization (Grant et al., 2014).

The inference is that when managers implement high-commitment and trust-building work practices, employees in return experience higher levels of job autonomy and involvement, and possibly innovation (Belt and Giles, 2009). It may be argued that where intrinsically motivating high-involvement practices (e.g. decision-making autonomy) are implemented, mutually reinforcing extrinsic high-commitment practices (e.g. benefits and rewards) are also required (Grant, 2017). There is enduring debate in the HRM-performance literature on which HR interventions and actions best constitute HPW practices, yet it is possible to surface dominant themes (Boxall, 2012). For example, through effective work design, supportive leadership, and continuous learning and development, employees can experience higher levels of workplace involvement, and may ultimately experience higher levels of job satisfaction and commitment (Belt and Giles, 2009). Five dominant themes, or HPW groupings, are drawn by the authors from the literature cited above, namely: autonomy and involvement; work organization and job design; team work and collaboration; leadership and management; and learning environment.

\section{Research Method}

The five HPW groupings identified above were empirically tested to investigate contemporary HPW within a range of organizations. The findings reported here are drawn from three UK-based qualitative case studies. Cases 1 and 2 are large public sector organizations. Case 3 is a smaller organization operating in the voluntary sector. The voluntary sector case was incorporated to explore HPW within a notably different organizational context, as advocated by Kalleberg et al. (2015). Data were collected via nine in-depth interviews with managers (three from each case) and three subsequent focus groups (one in each case). The focus groups comprised six, eight and four employee (non-manager) interviewees respectively. Ten questions (two per HPW grouping) were posed to all interviewees in a semi-structured format. The inductive data analysis process in each case was informed by Creswell (2014). Elemental to this were: close, repeated reading of the 
transcripts to appreciate meaning and inherent themes; then coding of the emergent themes to gather the data in each theme for closer scrutiny. Validity was addressed by triangulation of the themes from the two types of data collection and participants, together with each author self-reflecting on their positionality in interpreting the data. This was followed by peer debriefing which corroborated the authors' analysis of the data. Reliability was addressed by the authors regularly discussing their analysis and the cross-checking of codes with each other and the peer de-briefer. Illustrative, anonymous quotations from managers and employees are incorporated within the findings below, coded in each case to indicate the spread of quoted sources.

\section{Findings and Discussion}

While heavily regulated and prescriptive roles were viewed as being necessary within the risk-critical nature of cases 1 and 2, hierarchical structures and demarcated roles were perceived as potential inhibitors of job autonomy and involvement. A manager for example recognized that:

"We need to do things differently and encourage creativity to maintain the level of service... we have to allow people the space, time and freedom to act... We need to create the right conditions...permission to think and act and use initiative" (case 1).

In contrast, more lateral flexibility and project-based structures prevailed in case 3, allowing employees to move more fluidly between projects and teams. The notion of responsible autonomy surfaced within all cases as being complex - contentious even - and framed to a large extent by organizational legacy and culture. For example, "there are two sides here, senior managers think they empower employees, but employees themselves think they are bound by rules and regulations" (manager, case 2); and "I would like my manager to give me a bit more autonomy to not only gather information, but to use it, to trust what I'm saying is correct" (employee, case 2).

Interviewees reflected on having "nominal responsibility" (manager, case 3 ) for tasks, but not necessarily autonomy. An employee (case 3) explained that "within the necessary realms of control, you can still think outside of the box". Yet it was opined that "we have a great deal of autonomy, but there is a boundary...the line between boundaries of responsibility is often quite blurred" (employee, case 3).

Interviewees linked autonomy and involvement to the other HPW groupings. For instance, linking to work organization and job design, a number of manager and employee interviewees commented on the often restrictive nature of job descriptions. It was suggested that job descriptions could offer greater flexibility through becoming "more outcome-focused as opposed to task-driven" (manager, case 2), to facilitate increased autonomy and involvement in achieving work goals.

The use of team-based structures was also positively associated with job autonomy and achievement of work goals due to peer support and joint decision-making processes. It was posited that "teams are very much the decision makers and managers guide and influence that process" (employee, case 3). However, competition within teams, for example in promotion opportunities, was perceived by managers and employees to threaten team work. It was asserted, e.g., that "there are a number of people who do the same job and sometimes they compete for jobs...this makes people more reluctant to share information and knowledge" (manager, case 1). 
Leadership and management was also considered as a potential lever for, or inhibitor of, job autonomy, for instance through levels of delegation, control and trust. For it was recognized that "it's my responsibility as a leader to help connect people to what's going on in the organization" (manager, case 1). In contrast, leadership and management were considered important in the extent to which employees perceive the existence of a blame culture. Also, blame cultures were reported as restricting decision making. For example, "although we are allegedly a no blame organization, we...can be quick to point out mistakes and take action where people go wrong...this then leads to aversion to taking decisions" (manager, case 2).

It was acknowledged that a lack of job autonomy and involvement can in turn lead to "a lack of willingness to change and learn new skills" (manager, case 1). Therefore, autonomy can also be linked to organizational commitment and learning environment. Considering employees' interests more broadly in their commitment to learning and to developing their performance at work was signalled throughout the interviews, reflecting leadership and management. For instance, "we need to look at people more holistically to tap into their strengths and what excites them" (manager, case 1); and "if you can tap into things that people love doing and are passionate about, then they are so much more motivated to learn and perform" (manager, case 2).

\section{Conclusion}

The research findings validate the theoretical importance of the five HPW groupings. More, they imply a number of relationships within and between the five groupings, confirming the need to view the groupings collectively and dynamically. The groups of autonomy and involvement, together with leadership and management, arguably have particular importance as they are most often linked to the other groupings.

The five HPW groupings provide a foundation for further research to evaluate the dynamism within and across the groupings. They also offer practical types of HR interventions and actions for practitioners to reflect on and evaluate the strengths and weaknesses of HPW in their organizations.

\section{References}

Belt, V. and Giles, L. (2009), "High performance working: a synthesis of key literature", Evidence Report 4, UK Commission for Employment and Skills: Wath-upon-Dearne, UK.

Boxall, P. (2012), "High-performance work systems: what, why, how and for whom?" Asia Pacific Journal of Human Resources, Vol. 50 No. 2, pp. 169-186.

Creswell, J.W. (2014), Research design: qualitative, quantitative and mixed methods approaches $\left(4^{\text {th }}\right.$ ed.), London: Sage.

Grant, K. (2017), "HRM and high-performance workplaces", in Bratton, J. and Gold, J. (6 th $^{\text {th }}$ ed.), Human Resource Management: Theory and Practice, London: Palgrave, pp. 417-442.

Grant, K. and Maxwell, G.A. (2015), "High performance work practices: exploring manager and employee perceptions in Scotland", paper presented at $33^{\text {rd }}$ International Labour Process Conference, 13-15 April, Athens, available at: http://www.ilpc.org.uk/Portals/56/ilpc2015paperupload/ILPC2015paper-

ILP\%20HPWPs\%20article\%202015\%20(March)_20150407_123036.docx (accessed 23 June 2017). 
Page 5 of 5

Development and Learning in Organizations

1
2
3
4
5
6
7
8
9
10
11
12
13
14
15
16
17
18
19
20
21
22
23
24
25
26
27
28
29
30
31
32
33
34
35
36
37
38
39
40
41
42
43
44
45
46
47
48
49
50
51
52
53
54
55
56
57
58
59
60

Grant, K., Maxwell, G. and Ogden, S. (2014), "Skills utilization in Scotland: exploring the views of managers and employees", Employee Relations, Vol. 36 No. 5, pp. 458-479.

Kalleberg A.L., Marsden P.V., Reynolds J. and Knoke D. (2015), "Beyond profit? Sectoral differences in high-performance work practices", Work and Occupations, Vol.33 No.3, pp. 271-302. 